\title{
ACCESS TO DATA AND EMPLOYEE ACTIONS FOR INFORMATION SECURITY
}

doi: 10.2478/cqpi-2019-0006

Date of submission of the article to the Editor: 05/05/2019

Date of acceptance of the article by the Editor: $31 / 05 / 2019$

\author{
Żywiołek Justyna ${ }^{1}$ - orcid id: 0000-0003-0407-0826 \\ Alberto di Taranto ${ }^{2}$ - orcid id: 0000-0001-8189-4103 \\ ${ }^{1}$ Częstochowa University of Technology, Poland \\ ${ }^{2}$ CEO of Tyto srl, Italy
}

\begin{abstract}
Access to data is a nefralgic information security zone. On the one hand, we do everything to protect them against disclosure, and on the other hand, we need a new employee to provide data and information to be able to do their job.

Managing access to data in the enterprise significantly affects the level of security in all areas of activity. The article presents the results of research in the field of security of policy objectives in a selected production company. The purpose of preliminary research is to analyze selected issues in the field of data access, control methods and employee responsibility.

The article discusses the results of research on the access to information by employees. Lack of access to the data paralyzes their work, but their excess causes information chaos and makes it difficult to make a decision. The research results clearly indicate that access to data is treated as a priority, forgetting about access to computer software, mobile devices, which can also be the security of the company.

Keywords: information security, mobile devices, data security, user safety
\end{abstract}

\section{INTRODUCTION}

Progress in the field of information technology and information exchange means that information security has become one of the elementary factors stimulating development contemporary economy, also leading to the transformation of industrial society into information (Tutton, 2015). The strategic significance stems from the fact that information available at the desired time can be a key factor of success, and in turn their lack can become the cause of many failures in the activities (Deneen, Shroff, 2011). To above, there is a need to care for such strategic assets, which are data and information, because they determine the advantage over other enterprises (Żywiolek, 2018). Access to data is not just about hiring an employee and assigning him duties. You must specify access to paper documents and IT system modules (Axelrod, Bayuk, Schutzer (eds.), 2009). Access to data is primarily related to the difficulty in distinguishing modules and creating habits in employees. 
In the study, employees of three large enterprises in the metallurgical industry, having production departments as well as trade departments participated. The survey was conducted with the help of a questionnaire and an in-depth interview. The questionnaire was completed by 154 employees, while 11 senior managers dealing with IT or company security participated in the interview.

This study is an introduction specifying how important is access to data on individual positions and the division of data into modules with the indication of positions that should be available to selected information satchels. Such conduct may constitute information security for the company.

\section{ACCESS CONTROL TO DATA}

Another element that was highlighted by manual workers was the availability of information, which states that only authorized persons can use it at a given place and time (Tallinn. Castelfranchi, Falcone, Marzo, 2010). The confidentiality of information is an element that has been considered the least important, i.e. an information security function providing access or lack of access (Syreyshchikova eds., 2019). Physical workers are not fully aware that information is a good that, for example, used by competitors can become a threat to the enterprise (Durodolu, 2016).

Also, white-collar workers assessed the company's security system. according to them, the integrity and availability of information are the most important elements. The diversity of responses was greater than that of manual workers due to the diversity of positions of the employees surveyed (Brandis et. al., 2016). The reliability of information has been considered the least important, the certainty that the information will reach the recipient. Mental workers took it for granted that the necessary information for work would be provided.

The next question was about how to control access to data (Figure 1).

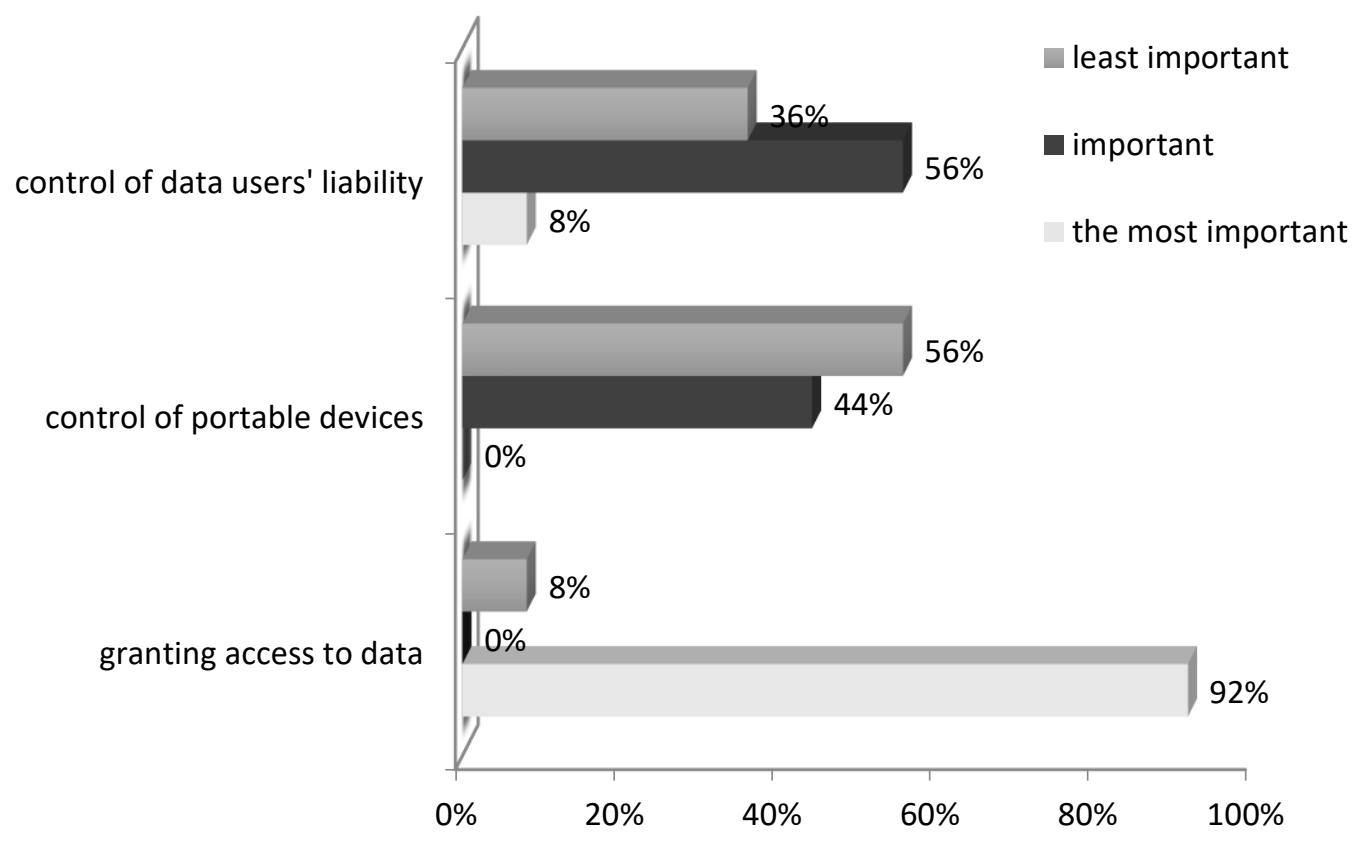

Fig. 1. Access control

Respondents in $92 \%$ responded that the most important thing is to give access to data. The answers regarding the control of mobile devices and the control of users' 
responsibility for data are quite different. In the examined enterprise there are job boards, to which, after the establishment of the enterprise security policy, the duties and responsibilities of the user of the data will be entered. The results of the research showing the dependencies between the position occupied and the responses regarding the method of controlling access to data in the surveyed enterprises are shown in Fig. 2 (for manual workers) and Fig. 3 (for white-collar employees).

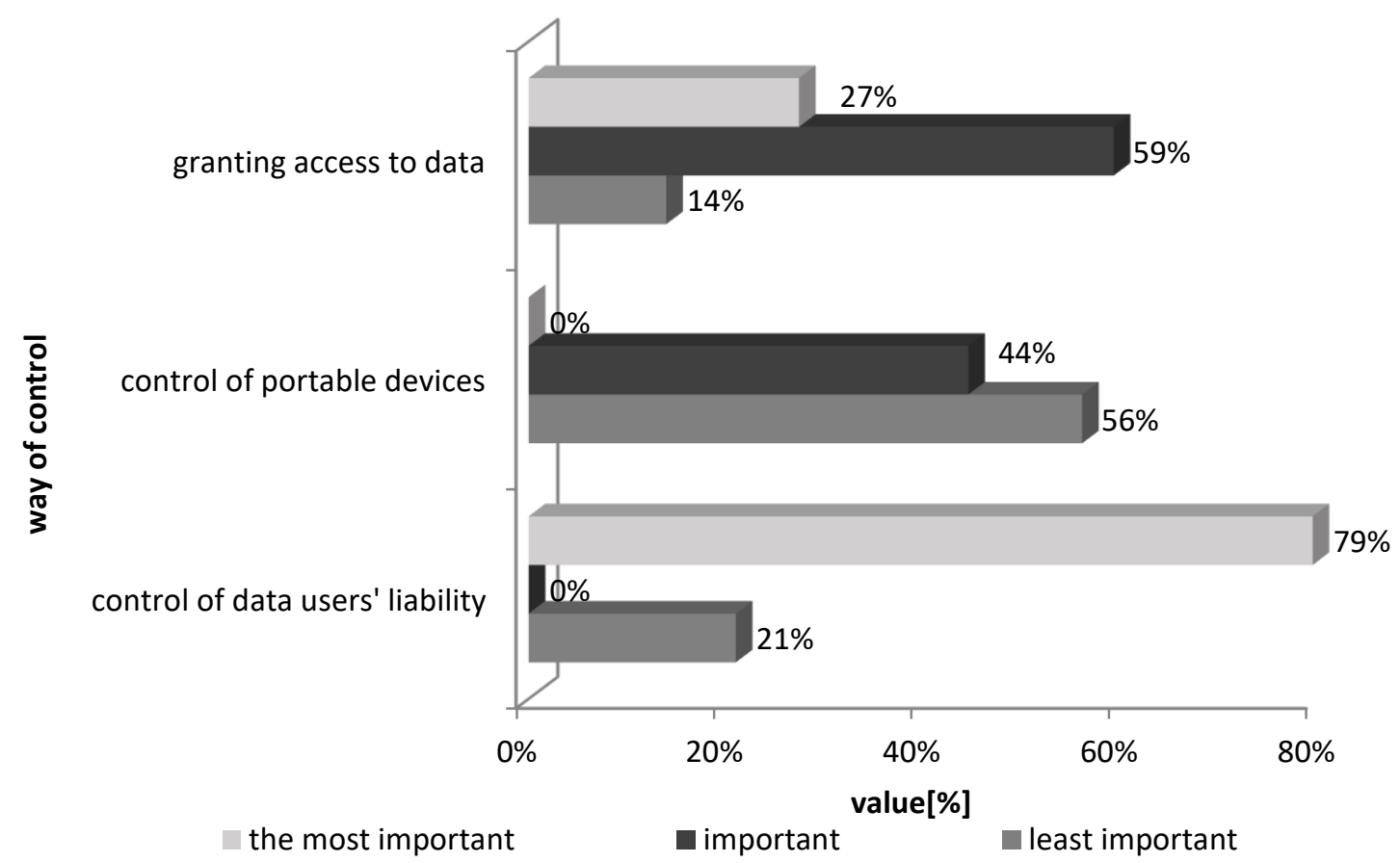

Fig. 2. Responsibility regarding the method of controlling access to data by manual workers

Physical workers believe that the most important thing is to give access to data. This should be done in accordance with the job card of the given position. Having strictly defined rules for giving access to data, it is easier to avoid mistakes and allocate too many accesses for a given employee. The remaining answers are already quite diverse, the control of mobile devices and the control of users' data responsibility are considered equally important. More varied answers were obtained in the case of white-collar workers (Figure 3). 


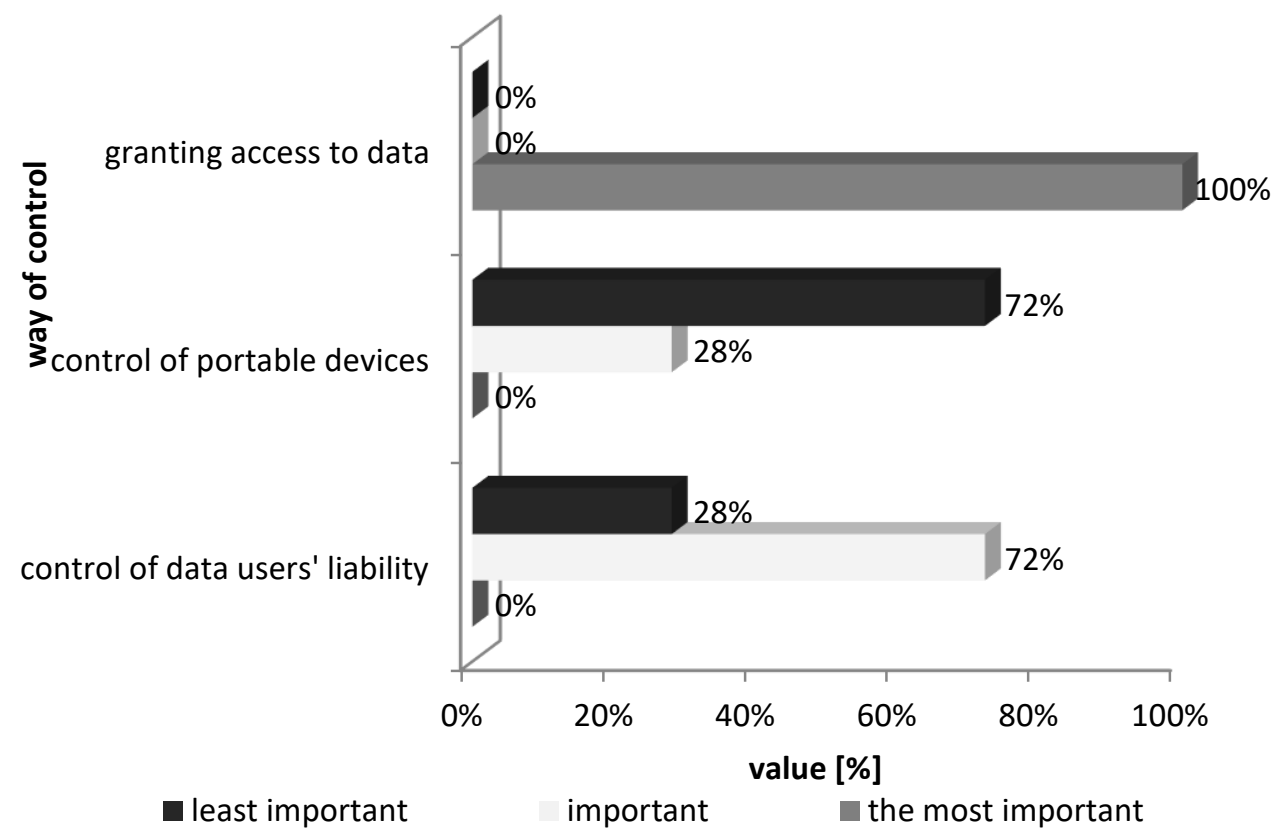

Fig. 3. Responsibility regarding the method of controlling access to data by white-collar workers

Mental workers also felt that granting access to data is the most important element that allows access control of data. Office employees are more aware of the assessment of individual components regarding access to data. They considered the least important control over mobile devices. They think that a computer with a password or a flash memory stick is not in danger and does not have to be controlled so carefully.

Another question related to the type of difficulties that an enterprise may encounter when implementing an enterprise security system will come into contact before conducting a risk analysis. Staff evaluation is presented in Figure 4.

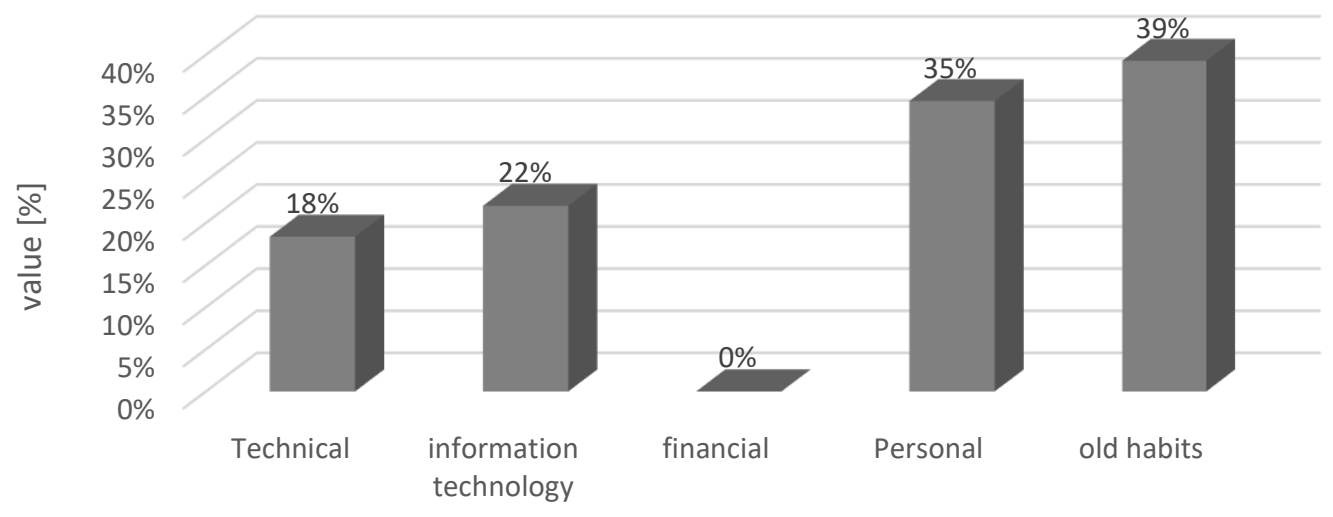

kind of difficulty

Fig 4. Difficulties in the implementation of security policy elements

The most common problems are the old employees' habits. It's hard to excuse employees sticking yellow cards with passwords or to encourage them to shut down computers every time they leave the room. However, these are necessary behaviors, and the information protection theory proposes to use in this case a specific pattern of behavior, which will be described in the further part of the paper devoted to security policy. 


\section{CONCLUSION}

Information, regardless of whether they are printed on paper, spoken during a conversation, stored in electronic form or sent using modern computer technology, constitute a valuable resource of every organization. Access to data provides employees with an employer specifying his duties. whereas security policy is a basic document regulating the company's operations in the area of information security. The implementation of the set goals is possible, among others by dividing IT systems into modules, which facilitates the allocation of access. It should also be emphasized that the role of individual employees in access to data is diverse and depends not only on the area of tasks performed, but also on the functions and levels of decision-making. The surveyed enterprises should take actions aimed at continuous improvement of the security policy by using information on shortcomings of employees who have access to data. The method of controlling access to data has been clearly defined in the procedure established after completing the preliminary survey in the form of a questionnaire. While discussing the conducted research in enterprises, the responsibility of both physical and intellectual employees in the surveyed enterprises was also specified. Documents, databases and software have been divided into modules. For example, accounting employees dealing with payouts for employees have access to the payroll module, staff, while employees of the same department dealing with receivables settlement have access to the invoice module, the billing program. Such a modular division avoids information chaos, facilitates the division of duties and settlement of tasks, and ensures the security of the company's operation if the employee is bribed by competitors or works against the enterprise.

\section{REFERENCES}

Axelrod, C.W., Bayuk, J.L., Schutzer D. (eds.), 2009. Enterprise Information, Security and Privacy, Artech House, Norwood.

Brandis K. et. al., 2016, A process framework for information security management "International Jurnal of Information Systems and Project Management", Vol 4, No 4.

Deneen C. C., Ng E. M., Shroff R. H., 2011. Analysis of the technology acceptance model in examining students' behavioural intention to use an eportfolio system "Australasian Jurnal of Educational Technology", No 27(4).

Durodolu, O., 2016. Technology Acceptance Model as a predictor of using information system' to acquire information literacy skills "Library Philosophy and Practice", November.

Tallinn. Castelfranchi C., Falcone R., Marzo F., 2010. Trust and relational capital "Computational and Mathematical Organization Theory", Vol 17, Issue 2, 2016.

Tutton J., 2010. Incident response and compliance: $A$ case study of the recent attacks, Information, Security Technical Report 15.

Żywiołek J., 2018. Monitoring of Information Security System Elements in the Metallurgical Enterprises, MATEC Web of Conferences, https://www.matecconferences.org/articles/matecconf/pdf/2018/42/matecconf_qpi2018_01007.pdf.

Syreyshchikova N. V., Pimenov D. Yu., Mikołajczyk T., Moldovan L., 2019. Information Safety Process Development According to ISO 27001 for an Industrial Enterprise, Procedia Manufacturing 32. 